\title{
Intercomparison of FY-3 and AIRS Gravity Wave Parameter Extraction Based on Three Methods
}

Shujie Chang ${ }^{1,2,3}$, Zheng Sheng ${ }^{1,2}$, Wei Ge ${ }^{1,2}$, Wei Zhang ${ }^{1,4}$, Yang $\mathrm{He}^{1,2}$, Zhixian Luo $^{1}$

5 'College of Meteorology and Oceanography, National University of Defense Technology, Nanjing, 210000, China

${ }^{2}$ Collaborative Innovation Center on Forecast and Evaluation of Meteorological Disasters, University of Information Science and Technology, Nanjing, 210044, China

${ }^{3}$ South China Sea Institute for Marine Meteorology, Guangdong Ocean University, Zhanjiang, 524088,

10 China

${ }^{4}$ China Satellite Maritime Tracking and Controlling Department, Jiangyin, 214431, China

" Corresponding author.

Correspondence to: Zheng Sheng (19994035@sina.com).

15 Abstract. Two types of temperature profile products from the FY-3 (FengYun-3) satellite system, using GNOS and VASS, together with AIRS operational Level 2 data, are used to compare and analyze gravity wave parameters. The advantages and disadvantages of these three types of temperature profile data for gravity wave parameter extraction are determined, based on three extraction methods: vertical sliding average, double-filter and single-filter. By comparing the three methods, the conditions under which each dataset can be applied are obtained. Accurate gravity wave disturbance profiles cannot be obtained using the vertical sliding average method. The double-filter method can extract gravity waves in a vertical wavelength range from 2 to $10 \mathrm{~km}$. The single-filter method can obtain gravity wave disturbances with vertical wavelengths less than $8 \mathrm{~km}$. For all three gravity wave parameter extraction methods, the GNOS temperature profile product performs better in the lower layer of 5-35 km. From 35 to $65 \mathrm{~km}$ the AIRS temperature profile product is better than GNOS. Using the single-filter method, GNOS and AIRS filter out the vertical linear trend in the disturbance profile well, reflecting the advantages of a single filter. The vertical resolution of VASS is lower, but larger vertical scale components are retained.

Keywords: Gravity Wave; FY-3; AIRS; Extraction Methods. 
chemistry, and dynamics of the stratosphere and mesosphere (Fritts and Alexander, 2003). The generation of gravity waves depends on topographic and atmospheric conditions: they are primarily generated due to orography (Smith, 1985; Durran and Klemp, 1987; Nastrom and Fritts, 1992), deep convection (Pfister et al., 1986; Tsuda et al., 1994; Alexander and Pfister, 1995; Alexander and Vincent, 2000), wind shear (Fritts and Nastrom, 1992; Plougonven et al., 2003; Wu and Zhang, 2004) and wave-flow interactions (Fritts and Alexander, 2003; Vadas et al., 2003). During their upward propagation, since the kinetic energy is inversely proportional to the square root of the atmospheric density, the amplitude of the disturbance increases exponentially. When a critical layer is reached, this leads to fragmentation, so that the momentum and energy are released into the background atmosphere, resulting in a change to the background circulation that affects the thermodynamics and dynamics of the atmosphere both locally and globally (Li and Yi, 2007; Zhang et al., 2010; Tang et al., 2014). During the whole lifecycle of gravity waves, the occurrence and development of various mesoscale weather systems are profoundly affected by their generation, development and fragmentation processes, which are often triggers for various meso-scale convective systems. Gravity waves also play a significant role in the adjustment and evolution of atmospheric circulation. At the same time, gravity waves are the link between the lower atmosphere and the middle and upper atmosphere (Holton, 1982; Lamarque et al., 1996; Sprenger et al., 2007; Pan et al., 2010). At present, most global atmospheric models use gravity wave parameterizations. The gravity wave parameterization scheme is an essential module in almost all atmospheric general circulation models (GCMs), including for middle atmosphere processes (Fritts and Alexander, 2003). Generally speaking, the importance of stratospheric gravity waves in atmospheric circulation modeling and numerical weather prediction mode has two main aspects. First, by using data obtained from various observation methods, information about stratospheric gravity waves can be extracted, and their distribution characteristics analyzed, and this is necessary for accurately constructing and executing the atmospheric model. Second, considering the subgrid effects of stratospheric gravity waves is important for constructing the parameterization scheme itself (Fritts and Alexander, 2003; Kim et al., 2010).

During aircraft flight, since the scale of the gravity waves is similar to the typical aircraft size, stratospheric gravity waves have a strong influence on the aircraft, and can periodically cause it to vibrate. After the gravity wave breaks, the turbulent motion generated can also impact the aircraft motion irregularly but frequently, affecting the flight path and causing safety issues. Because of the unique environmental characteristics of the stratosphere, any strong disturbances will also bring flight safety problems to Low Earth Orbit (LEO) satellites (Lane et al., 2003; Williams and Joshi, 2013). In general, improving the understanding of gravity waves in the stratosphere cannot be neglected. On the one hand, it is essential for improving the accuracy of atmospheric circulation models and the numerical weather prediction; on the other hand, it is an urgent requirement for flight safety. 
Satellite observation has been widely used in the study of gravity waves. Fetzer and Gille (1994) demonstrated for the first time that satellite remote sensors can observe gravity wave systems. been studied by using GPS/MET occultation data (Tsuda et al., 2000), CHAMP GPS occultation data (Ratnam et al., 2004; Torre et al., 2006), Aura satellite MLS (Microwave Limb Sounder) observations (Wu and Eckermann, 2008) and COSMIC GPS occultation data (Xiao and Hu, 2010). Those studies have shown that the distribution of gravity waves changes significantly not only with altitude, but also with latitude, longitude and topography. In order to construct a more systematic and reliable gravity wave model, Ern et al. (2014) used SABER's 11-year observation data and HIRDLS (High Resolution Dynamics Limb Sounder) two-year observation data to study the contribution of gravity waves to the equatorial quasi-biennial oscillation (QBO). Because of the increasing accuracy, vertical resolution and data density of COSMIC satellite data, current observations of COSMIC satellites are widely used in the study of short-term atmospheric gravity waves in the global stratosphere (Alexander et al., 2008; Wang and Alexander, 2009; McDonald, 2012). However, there is still a lack of research on stratospheric atmospheric gravity wave activity based on long-term observations of COSMIC satellites. Liang et al. (2014) determined some characteristics of gravity waves in the stratosphere by using the temperature profile data from January 2007 to December 2012. In 2002, NASA launched the Aqua satellite to combine AMSU (The Advanced Microwave Sounding Unit) with AIRS (The Atmospheric Infrared Sounder), forming a high-resolution coupled temperature detection system. The horizontal resolution is three times higher than that of AMSU-A, enabling AIRS to measure the two-dimensional horizontal structure of gravity waves (Alexander, et al., 2010).

Meanwhile, the long-term time series of AIRS radiation data provides further opportunities for studying the frequency of gravity waves and other climatic features on a global scale (Gong et al., 2012;

Hoffmann et al., 2013, 2014). Previously, the temperatures retrieved by AIRS were not usually used for gravity wave studies, mainly because of their limited horizontal resolution. However, a high spatial resolution stratospheric three-dimensional temperature field can be obtained from AIRS radiation Level 1 data. The high-resolution AIRS temperature dataset obtained by Hoffmann and Alexander (2009) is considered to be the best choice for stratospheric gravity wave research. In the meanwhile, a comparison between the AIRS high-resolution stratospheric temperature retrieval, the AIRS operational Level 2 data, and ERA-Interim reanalyses is performed (Meyer and Hoffmann, 2014; Dee et al., 2011), which showed that the AIRS high-resolution retrievals reproduce means with good accuracy. Yao et

al. (2015) used the AIRS observation data to obtain the characteristics of stratospheric gravity waves in East Asia in summer. Some study show the estimating directional gravity wave momentum flux which is applied 3-D spectral analysis techniques to the AIRS high-resolution retrievals (Ern et al., 2017; Wright et al., 2017)Gravity wave propagation processes have also been analyzed using AIRS (e.g. Sun 
et al., 2018; Wang et al., 2018). Meyer et al. (2018) demonstrated the effectiveness of AIRS for gravity wave observation by comparing AIRS and HIRDLS temperature profiles. In summary, it is possible to extract good gravity wave signals from temperature profiles retrieved by AIRS.

It is worth mentioning that Hoffmann and Alexander (2009) found that the minimum vertical wavelength of their high-resolution AIRS retrieval is about $10-15 \mathrm{~km}$ in the stratosphere. For the temperature retrievals presented, they adapted the Juelich Rapid Spectral Simulation Code (JURASSIC). The simulations include only AIRS channels where radiance emissions of carbon dioxide dominate, and contributions of interfering species or aerosols can be neglected in comparison with noise. Hindley et al.(2019) chosen vertical regular distance grid is over the range $\mathrm{z}=10-70 \mathrm{~km}$ in steps of $3 \mathrm{~km}$, close to the original grid of Hoffmann and Alexander (2009), which comes to the same results. In order to extract gravity wave signals with a vertical wavelength of less than $10 \mathrm{~km}$, the AIRS operational Level 2 data is used in this paper. In combination with the Advanced Microwave Sounding Unit (AMSU) and the Humidity Sounder for Brazil (HSB), AIRS Level 2 data constitutes an innovative atmospheric sounding group of visible, infrared, and microwave sensors. It is a new product produced using AIRS IR only because the radiometric noise in AMSU channel 4 started to increase significantly (since June 2007). The Support Product includes higher vertical resolution profiles of the quantities found in the Standard Product, plus intermediate outputs (e.g., microwave-only retrieval), research products such as the abundance of trace gases, and detailed quality assessment information (More information can be found online at https://disc.gsfc.nasa.gov/datasets/AIRS2SUP_V006). The Support Product profiles contain 100 levels between 1100 and $.016 \mathrm{mb}$, which will be further introduced in section 2 .

In China, the FY-3C satellite was launched at the Taiyuan Satellite Launch Center on September 23,

1252013 , at 11:07 am. The FY-3 series is the second generation of polar orbiting meteorological satellites in China. The goal is to observe the global atmosphere and its geophysical properties on a whole-weather, multi-spectral and three-dimensional scale. Recently, FY-3 has been used for a preliminary study on gravity waves (Yao et al., 2019), but its products have not been systematically applied to gravity wave research. In particular, there has been no research published on how to optimally analyze the gravity wave parameters using FY-3 products. Therefore, this paper aims to study the advantages of the FY-3 satellite in obtaining stratospheric gravity wave parameters, in order to enable FY-3 products to be effectively applied to the study of gravity waves in the future. The two types of FY-3 temperature profile products, with GNOS and VASS, together with AIRS operational Level 2 data, are used to compare and analyze gravity wave parameters. The advantages and disadvantages of these three types of temperature profile data in gravity wave parameter extraction are determined. 


\section{Data and method}

\subsection{AIRS Level 2 data}

The Atmospheric Infrared Sounder (AIRS) on the Aqua in the Earth observation system is designed to measure the Earth's atmospheric temperature profiles on a global scale, which covers a wide band of observation the brightness temperature: $3.74 \mu \mathrm{m}$ to $4.61 \mu \mathrm{m}, 6.20 \mu \mathrm{m}$ to $8.22 \mu \mathrm{m}$, and $8.8 \mu \mathrm{m}$ to 15.4 $\mu \mathrm{m}$, totally in 2378 channel. For studies of atmospheric gravity waves, AIRS radiance measurements are suitable, because it can provide nearly continuous measurement coverage since September 2002.

The Level 2 data start from August 312002 to present, the height ranging from 0 to $77 \mathrm{~km}$. The vertical profiles of temperature for 100 levels, in $\mathrm{km}$, are shown in Table 1. From 0 to $35 \mathrm{~km}$, the vertical resolution can be as low as $1 \mathrm{~km}$. From 35 to $50 \mathrm{~km}$, the vertical resolution decreases to $2 \mathrm{~km}$.Above $55 \mathrm{~km}$, the vertical resolution decreases rapidly. It shows that operational Level 2 data can extract gravity wave signals with a vertical wavelength of less than $5 \mathrm{~km}$ from 0 to $35 \mathrm{~km}$ which contains small-scale information.

150

Table 1. Heights adopted for AIRS 100 levels (in km).

\begin{tabular}{|c|c|c|c|c|c|c|c|}
\hline $\begin{array}{l}\text { Level } \\
\text { number }\end{array}$ & $\begin{array}{l}\text { height } \\
\mathrm{km}\end{array}$ & $\begin{array}{l}\text { Level } \\
\text { number }\end{array}$ & $\begin{array}{l}\text { height } \\
\mathrm{km}\end{array}$ & $\begin{array}{l}\text { Level } \\
\text { number }\end{array}$ & $\begin{array}{l}\text { height } \\
\mathrm{km}\end{array}$ & $\begin{array}{l}\text { Level } \\
\text { number }\end{array}$ & $\begin{array}{l}\text { height } \\
\mathrm{km}\end{array}$ \\
\hline 1 & 77.256844 & 31 & 23.337944 & 61 & 9.0900583 & 91 & 1.1147099 \\
\hline 2 & 71.172173 & 32 & 22.663448 & 62 & 8.7559423 & 92 & 0.90581858 \\
\hline 3 & 66.311028 & 33 & 22.009609 & 63 & 8.4278097 & 93 & 0.69977981 \\
\hline 4 & 62.268707 & 34 & 21.375278 & 64 & 8.105485 & 94 & 0.4965359 \\
\hline 5 & 58.814564 & 35 & 20.759438 & 65 & 7.7887945 & 95 & 0.29603451 \\
\hline 6 & 55.795654 & 36 & 20.161093 & 66 & 7.477581 & 96 & 0.098219335 \\
\hline 7 & 53.117287 & 37 & 19.579374 & 67 & 7.1716838 & 97 & -0.096958578 \\
\hline 8 & 50.712391 & 38 & 19.013428 & 68 & 6.8709564 & 98 & -0.28955156 \\
\hline 9 & 48.529358 & 39 & 18.462509 & 69 & 6.5752563 & 99 & -0.47960705 \\
\hline 10 & 46.532829 & 40 & 17.925901 & 70 & 6.284451 & 100 & -0.66717106 \\
\hline 11 & 44.692795 & 41 & 17.402946 & 71 & 5.9984012 & & \\
\hline 12 & 42.987553 & 42 & 16.893023 & 72 & 5.7169886 & & \\
\hline 13 & 41.399193 & 43 & 16.395557 & 73 & 5.4400892 & & \\
\hline 14 & 39.91291 & 44 & 15.910015 & 74 & 5.1675873 & & \\
\hline 15 & 38.516754 & 45 & 15.435884 & 75 & 4.8993726 & & \\
\hline 16 & 37.200558 & 46 & 14.972706 & 76 & 4.6353397 & & \\
\hline 17 & 35.956245 & 47 & 14.52003 & 77 & 4.3753824 & & \\
\hline 18 & 34.776352 & 48 & 14.077447 & 78 & 4.1194057 & & \\
\hline 19 & 33.654861 & 49 & 13.644554 & 79 & 3.867311 & & \\
\hline 20 & 32.586479 & 50 & 13.220989 & 80 & 3.6190069 & & \\
\hline
\end{tabular}




$\begin{array}{lrllll}21 & 31.566605 & 51 & 12.806409 & 81 & 3.3744059 \\ 22 & 30.591127 & 52 & 12.400471 & 82 & 3.1334248 \\ 23 & 29.656567 & 53 & 12.002877 & 83 & 2.8959768 \\ 24 & 28.759758 & 54 & 11.613328 & 84 & 2.6619873 \\ 25 & 27.897917 & 55 & 11.231546 & 85 & 2.4313765 \\ 26 & 27.068544 & 56 & 10.857268 & 86 & 2.2040715 \\ 27 & 26.269417 & 57 & 10.490239 & 87 & 1.9799997 \\ 28 & 25.498541 & 58 & 10.130228 & 88 & 1.7590938 \\ 29 & 24.75407 & 59 & 9.7770014 & 89 & 1.5412855 \\ 30 & 24.034367 & 60 & 9.4303474 & 90 & 1.3265123\end{array}$

\subsection{FY-3 temperature profile}

The Level 2 data of FY-3 include atmospheric temperature profiles from the Global Navigation Occultation Sounder (GNOS) and the Vertical Atmospheric Sounder System (VASS) (Liao et al., 2016;

155 Yao et al., 2019).

GNOS is one of the remote sensing instruments on the FY-3 satellite. The GNOS Atmospheric

Temperature Profile (ATP) products provide the atmospheric moisture profile and auxiliary data for a single occultation. The products include a record of time, position of perigee point, temperature and pressure. The data range from June 1, 2014, to the present, and the height ranges from 0 to $65 \mathrm{~km}$; this is generally used as the final atmospheric occultation product (Liao et al., 2016). The vertical profiles of temperature for 60 levels, in $\mathrm{km}$, are shown in Table 2. From 0 to $35 \mathrm{~km}$, the vertical resolution can be as low as $1 \mathrm{~km}$. From 35 to $50 \mathrm{~km}$, the vertical resolution decreases to $2 \mathrm{~km}$.Above $50 \mathrm{~km}$, the vertical resolution decreases rapidly. It shows that GNOS can extract gravity wave signals with a vertical wavelength of less than $5 \mathrm{~km}$ from 0 to $35 \mathrm{~km}$ which contains small-scale information. More instruments information can be found online at http://www.nsmc.org.cn/NSMC/Home/Index.html.

Table 2. Heights adopted for GNOS 60 levels (in km).

\begin{tabular}{rlrlrl}
\hline $\begin{array}{l}\text { Level } \\
\text { number }\end{array}$ & $\begin{array}{l}\text { height } \\
\mathrm{km}\end{array}$ & $\begin{array}{l}\text { Level } \\
\text { number }\end{array}$ & $\begin{array}{l}\text { height } \\
\mathrm{km}\end{array}$ & $\begin{array}{l}\text { Level } \\
\text { number }\end{array}$ & $\begin{array}{l}\text { height } \\
\mathrm{km}\end{array}$ \\
\hline 1 & 63.45001732 & 21 & 21.38025447 & 41 & 4.685979736 \\
2 & 56.03636747 & 22 & 20.12922932 & 42 & 4.165835684 \\
3 & 51.94624156 & 23 & 18.94540984 & 43 & 3.67720236 \\
4 & 48.66232094 & 24 & 17.82621887 & 44 & 3.220883386 \\
5 & 45.96642879 & 25 & 16.77031706 & 45 & 2.79777204 \\
6 & 43.6833421 & 26 & 15.76907568 & 46 & 2.40774986 \\
7 & 41.68826032 & 27 & 14.81382696 & 47 & 2.049966708 \\
8 & 39.89239239 & 28 & 13.90102507 & 48 & 1.723919046 \\
9 & 38.23446611 & 29 & 13.0306026 & 49 & 1.429523995
\end{tabular}




\begin{tabular}{lrrrrr}
10 & 36.66612868 & 30 & 12.20142995 & 50 & 1.166710912 \\
11 & 35.14575249 & 31 & 11.40375472 & 51 & 0.934810441 \\
12 & 33.64531691 & 32 & 10.62818736 & 52 & 0.732656862 \\
13 & 32.17294806 & 33 & 9.873070715 & 53 & 0.559253834 \\
14 & 30.75312805 & 34 & 9.138710471 & 54 & 0.413602711 \\
15 & 29.37799749 & 35 & 8.425806957 & 55 & 0.294295707 \\
16 & 28.01655026 & 36 & 7.73576406 & 56 & 0.199404957 \\
17 & 26.6607753 & 37 & 7.070353414 & 57 & 0.126575756 \\
18 & 25.31667268 & 38 & 6.431115179 & 58 & 0.073026989 \\
19 & 23.98785926 & 39 & 5.819472775 & 59 & 0.035497364 \\
20 & 22.67640744 & 40 & 5.237303433 & 60 & 0.010146927 \\
\hline
\end{tabular}

The VASS Atmospheric Vertical Profile (AVP) product includes global atmospheric temperature and

170 humidity profiles retrieved from 4 MWTS (Micro Wave Temperature Sounder) microwave channels, 5

MWHS (Micro Wave Humidity Sounder) microwave channels and a VIRR cloud mask, which has been matched onto pixels of MWHS. It contains latitude, longitude, land-sea mask, land cover and surface height, solar zenith angle, solar azimuth angle, satellite zenith angle and satellite azimuth angle with 98 MWHS pixels per scan line. Meanwhile, brightness temperature of MWTS, brightness

175 temperature of MWHS, cloud percentage atmospheric temperature and humidity profile on each pixel are also included in the database. The data range from June 1, 2014, to the present, and the height ranges from 0 to $65 \mathrm{~km}$; the uses of this product include weather analysis, data assimilation in numerical weather and climate prediction and research on climate change.

The vertical profiles of temperature for 43 levels, in $\mathrm{km}$, are shown in Table 3 . From 0 to $20 \mathrm{~km}$, the vertical resolution can be as low as $1 \mathrm{~km}$. From 20 to $30 \mathrm{~km}$, the vertical resolution decreases to $2 \mathrm{~km}$. Above $30 \mathrm{~km}$, the vertical resolution decreases rapidly. It shows that VASS can extract gravity wave signals with a vertical wavelength of less than $5 \mathrm{~km}$ from 0 to $20 \mathrm{~km}$.

Table 3. Heights adopted for VASS 43 levels (in km).

\begin{tabular}{rlrlrl}
\hline $\begin{array}{l}\text { Level } \\
\text { number }\end{array}$ & \multicolumn{1}{l}{ height } & $\begin{array}{l}\text { Level } \\
\text { number }\end{array}$ & $\begin{array}{l}\text { height } \\
\mathrm{km}\end{array}$ & $\begin{array}{l}\text { Level } \\
\text { number }\end{array}$ & $\begin{array}{l}\text { height } \\
\mathrm{km}\end{array}$ \\
\hline 1 & 64.4723826 & 21 & 11.46486171 & 41 & 0.099402446 \\
2 & 56.78209658 & 22 & 10.50722427 & 42 & -0.03769831 \\
3 & 50.85101156 & 23 & 9.601219687 & 43 & -0.09248632 \\
4 & 45.9989813 & 24 & 8.747674345 & & \\
5 & 41.66570684 & 25 & 7.943304147 & & \\
6 & 37.98305517 & 26 & 7.184692583 & & \\
7 & 34.73291591 & 27 & 6.470260325 & & \\
8 & 31.96164631 & 28 & 5.794754587 & & \\
9 & 29.49189669 & 29 & 5.159693477 & & \\
10 & 27.24554265 & 30 & 4.557322032 & &
\end{tabular}




$\begin{array}{rrrr}11 & 25.20608004 & 31 & 3.990314884 \\ 12 & 23.36755808 & 32 & 3.453192391 \\ 13 & 21.66113773 & 33 & 2.946894438 \\ 14 & 20.08986748 & 34 & 2.469776545 \\ 15 & 18.61482026 & 35 & 2.022179551 \\ 16 & 17.23927692 & 36 & 1.605011703 \\ 17 & 15.97261788 & 37 & 1.22047371 \\ 18 & 14.72613964 & 38 & 0.872596232 \\ 19 & 13.57532284 & 39 & 0.564675321 \\ 20 & 12.4865391 & 40 & 0.304738014\end{array}$

\subsection{Gravity wave extraction methods}

According to the linear theory of gravity waves, the atmospheric temperature profile $T(z)$ typically consists of two components: the background temperature profile $\bar{T}(z)$ and the disturbance part $T^{\prime}(z)$, which represents the gravity wave: $T(z)=\bar{T}(z)+T^{\prime}(z)$. Based on vertical filtering, previous research has adopted the following different processing methods in specific operations. 1: Vertical sliding average method. Using a sliding window with a height of $8 \mathrm{~km}$, the observed temperature profile is averaged to estimate the background temperature profile $\bar{T}$. Then the background temperature profile is subtracted from the original temperature profile to obtain the gravity wave disturbance profile (Hocke and Tsuda, 2001). 2: Double-filter method. On a specific latitude and longitude grid, by taking all the valid observation data at a given height within 7 days, a weekly average profile of $\bar{T}(z)$ is obtained as the background temperature profile. The disturbance profile can be obtained by subtracting $\bar{T}(z)$ from the observed data. However, deviations occur when subtracting the average profile from a single profile. Therefore, the vertical linear trend is removed. A high-pass filter and a low-pass filter are then used separately to vertically filter out the large-scale and small-scale fluctuations, respectively, thereby obtaining the gravity wave disturbance $T^{\prime}(z)$ (Tsuda et al., 2000). 3: Single-filter method. First, the temperature is interpolated in height so that the vertical resolution is $1 \mathrm{~km}$, filtering out small-vertical-scale disturbances and noise. As a result, the vertical wavelength of the extracted gravity wave is less than $2 \mathrm{~km}$. Second, on a specific latitude and longitude grid, the average value of the temperature at each height within a 7-day period is calculated to give the background temperature $\bar{T}(z)$. Subtracting the background temperature from the original temperature, and removing the vertical linear trend, gives a temperature disturbance profile. Finally, a high-pass filter is used to filter this, to obtain the gravity wave temperature disturbance profile (Alexander et al., 2008).

Theoretically, the first method can extract gravity wave disturbances with a vertical wavelength of less than $8 \mathrm{~km}$, the second method can extract gravity waves in a vertical wavelength range from 2 to $10 \mathrm{~km}$, and the third method can obtain gravity wave disturbances in the vertical wavelength range from 2 to 8 
$\mathrm{km}$. In fact, some planetary scale disturbances, such as Kelvin waves, have vertical wavelengths of the same scale as gravity waves, so using these filtering methods means that the gravity wave disturbances obtained actually include a contribution from these other waves.

Based on the calculated gravity wave disturbances and background temperature, we can further calculate the square of the buoyancy frequency $N^{2}$ and the potential energy Ep of the gravity wave:

$$
\begin{aligned}
& N^{2}(z)=\frac{g}{\bar{T}}\left(\frac{\partial \bar{T}}{\partial z}+\frac{g}{c_{p}}\right) \\
& \mathrm{Ep}=\frac{1}{2}\left(\frac{g}{N}\right)^{2}\left(\frac{T^{\prime}}{\bar{T}}\right)^{2}
\end{aligned}
$$

where $g=9.8 \mathrm{~m} \cdot \mathrm{s}^{-2}, c_{p}=1005 \mathrm{~J} \cdot \mathrm{kg}^{-1} \cdot \mathrm{K}^{-1}$, and $\bar{T}$ is the background temperature.

\section{Comparison of FY-3 and AIRS based on three extraction methods}

\subsection{Vertical sliding average method}

Taking the observed temperature profile at $\left(74.65^{\circ} \mathrm{W}, 35.19^{\circ} \mathrm{N}\right)$ on January 1,2019 , as an example, the vertical sliding average method is first used to extract gravity wave disturbances from a single temperature profile. The steps are as follows:

(1) Using a sliding window with a height of $8 \mathrm{~km}$ and a sliding step length of $500 \mathrm{~m}$, the background temperature profile $\bar{T}$ is calculated.

(2) The background temperature profile $\bar{T}$ is subtracted from the original temperature profile $T$, to obtain the gravity wave disturbance profile.

Applying the sliding average with a window length of $8 \mathrm{~km}$ gives a background containing vertical scales greater than $8 \mathrm{~km}$. Therefore, the gravity wave disturbance obtained by subtracting the background profile retains those wave components with a vertical wavelength of less than $8 \mathrm{~km}$. For reference, first the calculation results of AIRS only are shown in Fig. 1. Then the calculation results from the FY-3 satellite and AIRS are compared in Fig. 2. 

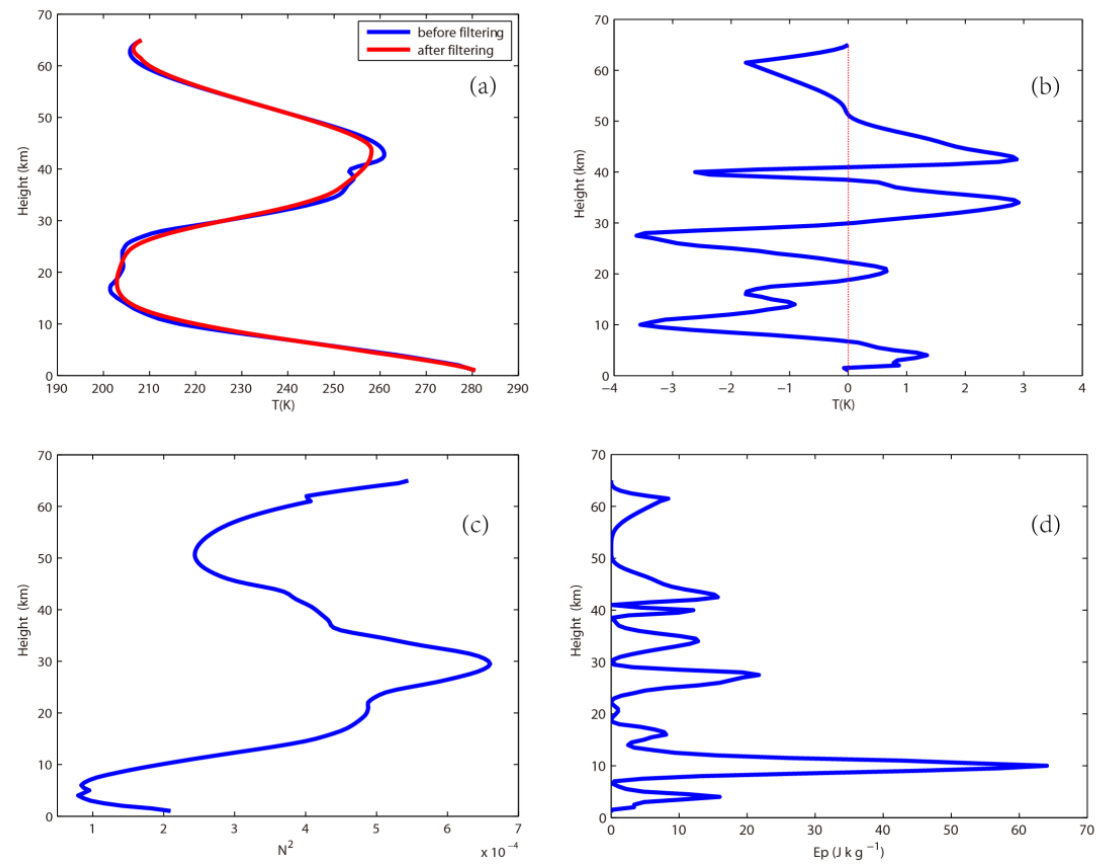

235 Figure 1. Temperature profile observed by AIRS at $74.65^{\circ} \mathrm{W}, 35.19^{\circ} \mathrm{N}$ on January 1,2019 . (a) The original atmospheric temperature profile (blue line) and the average temperature profile (red line). (b) The gravity wave temperature disturbance profile. (c) The gravity wave buoyancy frequency. (d) The gravity wave potential energy. Quantities are calculated using the vertical sliding average method.

The temperature profile observed by AIRS at $74.65^{\circ} \mathrm{W}, 35.19^{\circ} \mathrm{N}$ on January 1,2019 , is given in Fig. 1 . Figure 1a shows the original atmospheric temperature profile (blue line) and the average temperature profile (red line), which is calculated using a sliding average with a window length of $8 \mathrm{~km}$. The minimum in the original temperature profile indicates that the height of the tropopause is approximately $18 \mathrm{~km}$, with a temperature of approximately $-70{ }^{\circ} \mathrm{C}$. The background temperature shows the variation of temperature with height and gives the height range of the tropopause. Figure 1b shows the gravity wave disturbance profile, which is obtained by subtracting the background temperature profile $\bar{T}$ from the original temperature profile $T$. Due to the complex terrain and inhomogeneous surface, the temperature profile standard deviation of the data sets for heights ranging from 0 to $5 \mathrm{~km}$ is large: the temperature profiles here are poor (Liao et al., 2016). Therefore, we only consider the temperature profiles above $5 \mathrm{~km}$ in this study.

There are two maxima in the magnitude of the gravity wave disturbance, near $10 \mathrm{~km}$ in the troposphere and near the tropopause at $20 \mathrm{~km}$, with values around $-3 \mathrm{~K}$ and $1 \mathrm{~K}$. The maximum at $10 \mathrm{~km}$ reflects the role of the jet stream, and that at $20 \mathrm{~km}$ reflects the role of the tropopause. It can be seen from Fig. 

shows that the gravity wave disturbance also reaches a maximum near this height range. According to energy conservation, the sharp increase in the amplitude of the gravity wave disturbance in this height range cannot be physical. Above $20 \mathrm{~km}$, there is a significant wave structure in the vertical direction. The wavelengths of the gravity waves above $20 \mathrm{~km}$ are more than $8 \mathrm{~km}$, according to the vertical sliding average method. Below the tropopause, waves with smaller scales of 5-7 km are included. It should be noted that the sudden temperature changes with height near the tropopause cannot be smoothed out using the vertical sliding average method. It is speculated that the calculated gravity wave disturbance is amplified artificially by this method, resulting in an error. However, this error only occurs near the tropopause: above $20 \mathrm{~km}$, because the vertical variation of temperature is relatively flat, the neighboring temperatures contributing to the atmospheric background temperature are reasonably representative of that height, and the calculated gravity wave disturbance is therefore also highly reliable.

As is well known, the square of the buoyancy frequency represents the characteristics of the background atmosphere, while the gravity wave potential energy profile represents the transient behavior. From the calculated gravity wave disturbance, the square of the background atmospheric buoyancy frequency and the gravity wave potential energy profile are calculated by using Eqs. (1) and (2), and shown in Figs. 1c and 1d, respectively. The tropospheric buoyancy frequency gradually increases with height. Above the tropopause, the buoyancy frequency reaches a maximum value, which is similar to the results given by the previous study (Liao et al., 2016). The variation of the buoyancy frequency is related to the potential energy of the gravity wave. The potential energy of the gravity wave in the troposphere gradually decreases and reaches a minimum near the tropopause for the first time.

Although the gravity wave disturbance near the tropopause is amplified when the atmospheric background temperature profile is extracted using the vertical sliding average method, some components of the small-vertical-scale disturbances are retained: As well as fluctuations in the vertical with wavelengths 5-7 km, smaller-scale disturbances can also be seen.

Generally, the vertical sliding average method appears to retain high temporal resolution, because of the preservation of the atmospheric temperature profile at each time in the calculation. However, accurate gravity wave disturbance profiles are not available, mainly for two reasons: (1) near the tropopause, the gravity wave disturbance is artificially overestimated; (2) small-scale gravity waves and small-scale turbulence cannot be distinguished. 

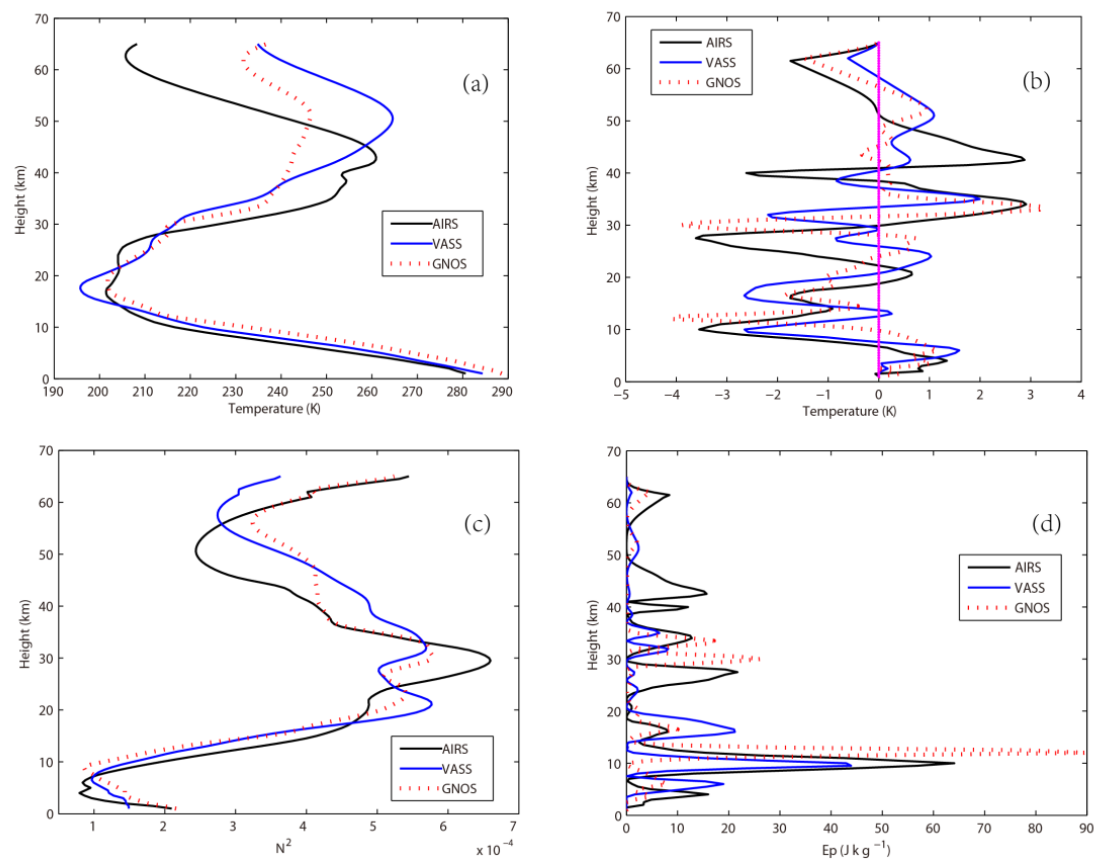

Figure 2. (a) Temperature profile at $74.65^{\circ} \mathrm{W}, 35.19^{\circ} \mathrm{N}$ on January 1 , 2019. (b) The gravity wave potential energy. Quantities are calculated using the vertical sliding average method. Black lines indicate AIRS, blue lines VASS, and red dotted lines GNOS.

The calculation results from applying the vertical sliding average method to of FY-3 satellite and AIRS data are compared in Fig. 2. On the whole, the three data sets can reflect the temperature variations. Below $20 \mathrm{~km}$, the temperature profile of the three data sets is consistent (Fig. 2a). From $20 \mathrm{~km}$ to 35 $\mathrm{km}$, the difference is gradually becomes larger. The VASS temperature profile includes global atmospheric temperature profiles retrieved from 4 MWTS (Micro Wave Temperature Sounder) microwave channels. Less energy is received near the ground, so the VASS temperature is of lower quality here. Above $35 \mathrm{~km}$, the temperature profiles of GNOS and AIRS are very different. This is because the GNOS SNR (Signal to Noise Ratio) decreases above $35 \mathrm{~km}$ : it generates some false signals, which reduce the quality of the temperature profile, showing that GNOS is applicable in the range 5-35 $\mathrm{km}$. From $35 \mathrm{~km}$ to $50 \mathrm{~km}$, the temperature profile of VASS is more consistent with that of AIRS than that of GNOS. Additionally the results for VASS are improved because its infrared spectrometer can receive more radiation signals in this height range. But because it's lower vertical resolution above 30 $\mathrm{km}$, the height of the maximum is not accurate.

In the height range $5-35 \mathrm{~km}$, the gravity wave disturbances from GNOS are consistent with AIRS, 
although the amplitude from GNOS is larger, up to $4 \mathrm{~K}$ near the tropopause (Fig. 2b). Within this height range, GNOS has an even stronger gravity wave signal than AIRS. And some components of the small-vertical-scale disturbances are retained: As well as fluctuations in the vertical with wavelengths 5-7 km, smaller-scale disturbances can also be seen.

The square of the buoyancy frequency and the gravity wave potential energy are compared in Figs. 2c and 2d, respectively. Although both GNOS and VASS follow similar behavior to AIRS, they have their own advantages. Below $35 \mathrm{~km}$, GNOS shows a stronger signal than VASS and AIRS, for both buoyancy frequency and gravity wave potential energy. With increasing height, the false signal from GNOS increases while VASS can obtain more radiant energy, so that the accuracy of VASS gradually increases relative to that of GNOS. But because of the lower vertical resolution of VASS above $30 \mathrm{~km}$, the height of the maximum is not accurate.

From the above results it can be concluded that, in the height range 5-35 km, the gravity wave signal

obtained by GNOS is better, and some components of the small-vertical-scale disturbances are retained: As well as fluctuations in the vertical with wavelengths $5-7 \mathrm{~km}$, smaller-scale disturbances can also be seen. The vertical resolution of VASS is lower, but larger vertical scale components are retained. The sliding average method can be applied at each height of a single temperature profile to obtain a rough background temperature. But the temperature disturbance based on this background temperature calculation method will inevitably contain some small-scale disturbances in the vertical direction, as well as other fluctuations, that are comparable in vertical scale to gravity waves, but differ in temporal scale, for example planetary waves. In addition, this method cannot accommodate drastic changes in background temperature in the vertical direction. For example, near the tropopause, the gravity wave disturbance potential energy is overestimated.

\subsection{Double-filter method}

In order to avoid the overestimation of the gravity wave disturbance near the tropopause from using the vertical sliding average method, the double-filter method is adopted. The steps are as follows:

(1) In the region $30^{\circ} \mathrm{N}-40^{\circ} \mathrm{N}, 70^{\circ} \mathrm{W}-90^{\circ} \mathrm{W}$, from January 1 to 7,2019 , the average temperature at each height is calculated and used as the background $\bar{T}$.

335 (2) The observed temperature profile at $\left(74.65^{\circ} \mathrm{W}, 35.19^{\circ} \mathrm{N}\right)$ on January 1,2019 , is taken as the original profile; the background is subtracted to obtain the disturbance profile.

(3) Linear fitting of the disturbance profile in the vertical direction is applied and the vertical linear trend is removed.

(4) A high-pass filter with a vertical wavelength of $10 \mathrm{~km}$ is applied.

340 (5) A low-pass filter with a vertical wavelength of $2 \mathrm{~km}$ is applied, to finally obtain the gravity wave disturbance profile. 
When using this method, the gravity wave disturbance obtained contains wave components with vertical wavelengths from $2 \mathrm{~km}$ to $10 \mathrm{~km}$. The calculation results for AIRS are given in Fig. 3, and then the calculation results from the FY-3 satellite and AIRS are compared in Fig. 4.
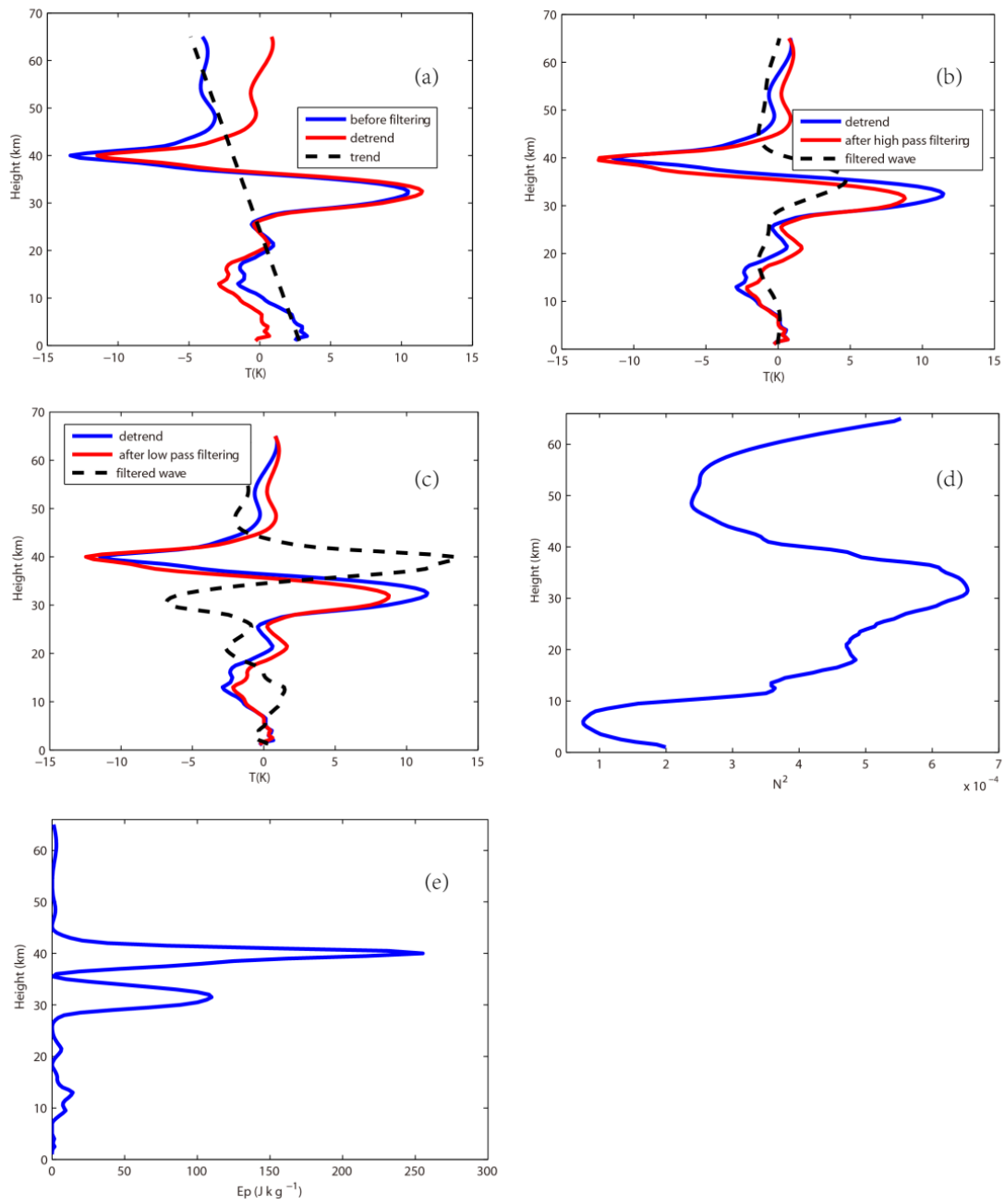

Figure 3. Results from the double-filter method. The physical quantities expressed in each panel refer to the descriptions in the text. original profile. It can be seen that the disturbance profile has a significant linear trend in the vertical direction, and the trend is clearly not caused by any gravity wave disturbance, so the vertical linear trend (black dotted line) is removed. The red line in Figs. $3 \mathrm{a}, 3 \mathrm{~b}$ and $3 \mathrm{c}$ is the temperature disturbance 
profile after removing the linear trend. From this, the filtering method is used to extract the gravity wave disturbance from a single disturbance profile. First, a high-pass filter with a vertical wavelength of $10 \mathrm{~km}$ is used to filter out large vertical disturbances, such as planetary waves. The results of the high-pass filter are shown in Fig. 3b. The red line is the same as in Fig. 3a, the blue line represents the profile after the high-pass filtering, and the black dashed line represents the large-scale disturbances, with vertical wavelength greater than $10 \mathrm{~km}$, filtered out by the high-pass filtering. The calculation result of the low-pass filtering is shown in Fig. 3c. The red line is the same as in Fig. 3a, the black dotted line indicates the small-scale disturbances, with vertical wavelength less than $2 \mathrm{~km}$, filtered out by the high-pass filtering, and the blue line indicates the final gravity wave disturbance profile obtained after the low-pass filtering.

Comparing the gravity wave disturbance profile (blue line in Fig. 3c) with the results in Fig. 1b (blue line), it can be seen that the gravity wave disturbance obtained by the vertical sliding average method has a richer vertical variation. This shows that the vertical sliding average method retains some small vertical scale disturbances: as well as fluctuations with vertical wavelengths of 5-7 km, smaller-scale disturbances can be seen. The gravity wave disturbance profile obtained by the double-filter method contains fewer small disturbances, and the main gravity wave has a vertical wavelength of about $8 \mathrm{~km}$ (blue line in Fig. 3c), which is similar to the results given by the previous study (Wang et al., 2019). Based on the calculated gravity wave disturbance, the square of the buoyancy frequency and the gravity wave potential energy profile are shown in Figs. 3d and 3e, respectively. The buoyancy frequency gradually increases with height in the troposphere. Above the tropopause, the buoyancy frequency reaches a maximum value, which is similar to the results given by the previous study (Liao et al., 2016;

375 Wang et al., 2019). The variation of the buoyancy frequency is also related to that of the potential energy of the gravity wave. 

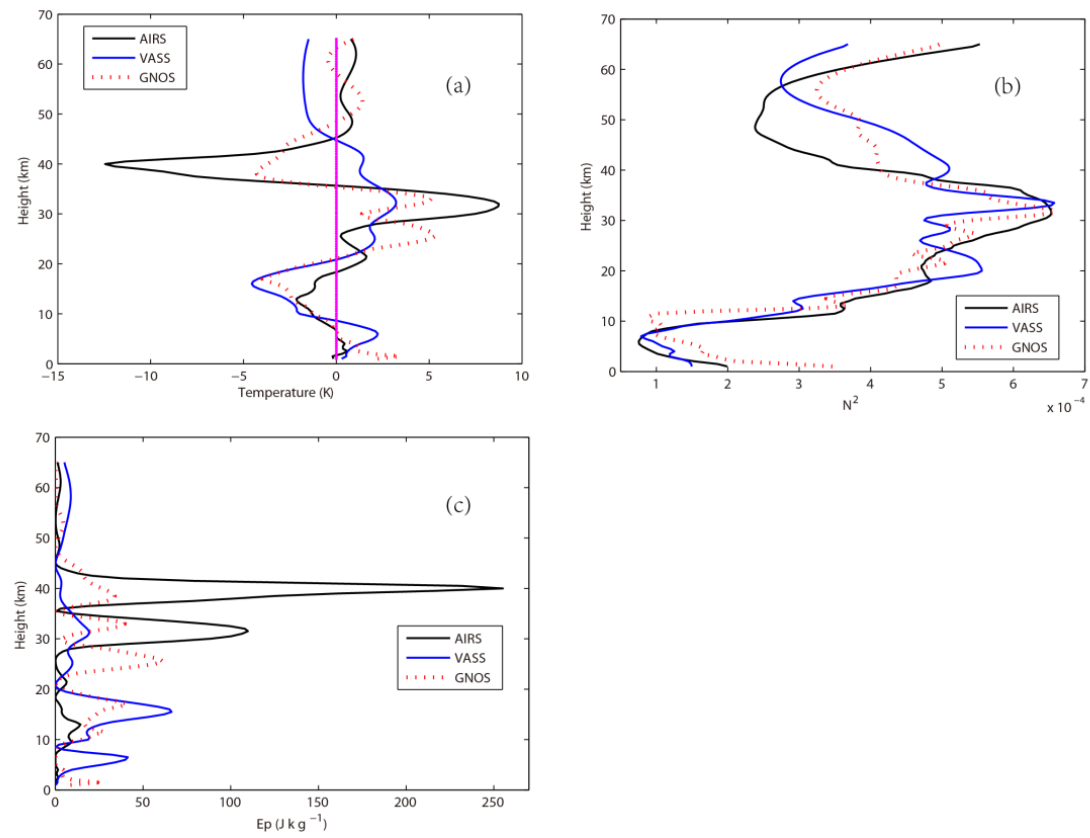

Figure 4. (a) Gravity wave temperature disturbance profile. (b) Gravity wave buoyancy frequency. (c)

Gravity wave potential energy. Quantities are calculated using the double-filter method. Black lines indicate AIRS, blue lines VASS, and red dotted lines GNOS.

The results of the double-filter method for extracting gravity waves are obtained based on AIRS. Then the calculation results from applying the double-filter method to FY-3 satellite and AIRS profiles are compared in Fig. 4.

Comparing the gravity wave disturbance profiles (Fig. 4a), in the height range 5-35 km, the gravity wave disturbance from GNOS is more consistent with that from AIRS. Meanwhile, AIRS and GNOS reflect some small-scale fluctuation information, with a wavelength of about $3-5 \mathrm{~km}$, which VASS is unable to obtain. Above $35 \mathrm{~km}$, AIRS can obtain more radiant energy, so that AIRS has an even stronger gravity wave signal than GNOS. However, because of the lower vertical resolution of VASS above $30 \mathrm{~km}$, the accuracy of VASS gradually decreases relative to that of GNOS and AIRS. Those are also seen with the calculated buoyancy frequency (Fig. 4b) and potential energy (Fig. 4c). As with the vertical sliding average method, from $5 \mathrm{~km}$ to $35 \mathrm{~km}$, GNOS has an even stronger gravity wave signal than AIRS. Above $35 \mathrm{~km}$, the gravity wave disturbance of AIRS is stronger.

In conclusion, in the height range $5-35 \mathrm{~km}$, the gravity wave signal obtained by GNOS is better, and in the range $35-65 \mathrm{~km}$, the gravity wave signal obtained by AIRS is better. The gravity wave disturbance extracted by the double-filter method is generally very accurate. The double-filter method can 
effectively suppress the large-scale background and small-scale disturbances in the temperature profile, so the obtained profile represents the sum of gravity wave disturbances with vertical wavelengths of 2

However, although the gravity wave potential energy at a certain height can be calculated accurately, the variation of the gravity wave potential energy with height is not so well reflected. But since this is not essential to the arguments developed in this article, it will not be pursued further here

\subsection{Single-filter method}

405 Taking the observed temperature profile at $74.65^{\circ} \mathrm{W}, 35.19^{\circ} \mathrm{N}$ on January 1,2019 , as an example, the single-filter method is used to extract the gravity wave disturbance profile from a single temperature profile. The steps are as follows:

(1) Temperature profiles are obtained in the region $30^{\circ} \mathrm{N}-40^{\circ} \mathrm{N}, 70^{\circ} \mathrm{W}-90^{\circ} \mathrm{W}$, from January 1 to 7 , 2019.

410 (2) Each profile is interpolated onto a vertical grid with a spacing of $1 \mathrm{~km}$. This is equivalent to low-pass filtering in the vertical direction, filtering out disturbances and noise in the temperature profile with vertical wavelengths less than $1 \mathrm{~km}$.

(3) Within the region $30^{\circ} \mathrm{N}-40^{\circ} \mathrm{N}, 70^{\circ} \mathrm{W}-90^{\circ} \mathrm{W}$, from January 1 to 7,2019 , the average temperature in each height is calculated and used as the background $\bar{T}$.

415 (4) The observed temperature profile at $74.65^{\circ} \mathrm{W}, 35.19^{\circ} \mathrm{N}$ on January 1,2019 , is taken as the original profile, and the background profile is subtracted to obtain the disturbance profile.

(5) A high-pass filter with a vertical wavelength of $8 \mathrm{~km}$ is used to filter the disturbance profile. Finally, the gravity wave disturbance profile is obtained containing wavelengths less than $8 \mathrm{~km}$. 

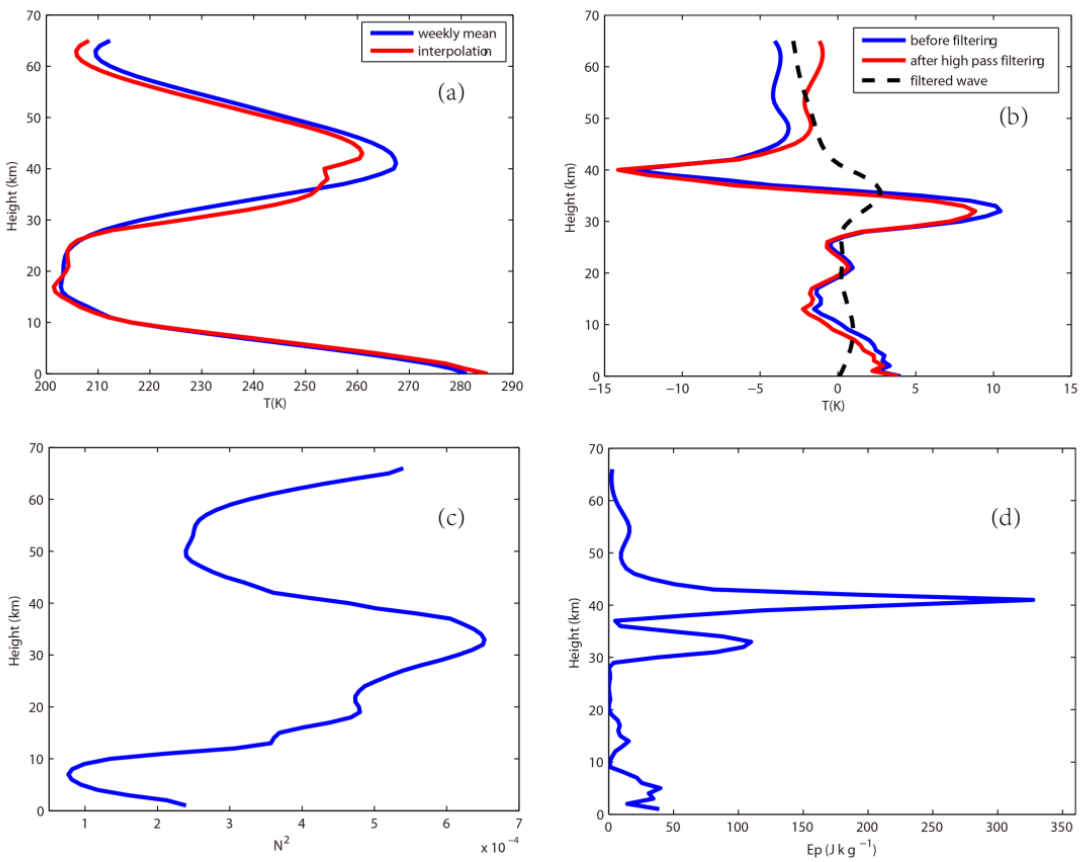

Figure 5. Results from the single-filter method. The physical quantities expressed in each panel refer to the descriptions in the text.

The calculation results for AIRS are given in Fig. 5, and the calculation results for the FY-3 satellite and AIRS are compared in Fig. 6.

In Fig. 5a, the red line represents the temperature profile after interpolation, and the blue line represents the 7-day average temperature profile. This shows that the interpolation in the vertical direction weakens the sharp vertical variation of the atmospheric temperature near the tropopause, which reduces the error caused by the calculation for extracting the gravity wave disturbance. However, the calculated disturbance profile still has a significant linear trend in the vertical direction, since only the time average is removed. A high-pass filter can be used to remove wave components with large vertical scales.

The result of the high-pass filtering is shown in Fig. 5b. The blue line in the figure is the temperature disturbance profile before filtering, the red line is the gravity wave temperature disturbance profile after filtering, and the black dashed line is the large-scale background removed by the filter. The vertical variation trend of the obtained gravity wave disturbance is consistent with the results obtained using the double-filter method in Fig. 3c. Overall, there are little differences in the absolute value and vertical wavelength of the gravity wave disturbance obtained by the two methods. The absolute value of gravity wave disturbance obtained by the single-filter method is similar to that obtained by the double-filter 

shows that there are many small-vertical-scale gravity waves in the upper troposphere and lower stratosphere.

Based on the calculated gravity wave disturbance, the square of the buoyancy frequency and the gravity wave potential energy profiles are shown in Figs. $5 \mathrm{c}$ and $5 \mathrm{~d}$, respectively. The vertical trend and magnitude of $N^{2}$ are generally consistent with the results of Fig. 3d. The variation of the buoyancy frequency is also related to that of the potential energy of the gravity wave e, which is similar to the results given by the previous study (Liao et al., 2016; Wang et al., 2019).

The results of the single-filter method for extracting gravity waves, for the FY-3 satellite and AIRS, are compared in Fig. 6.
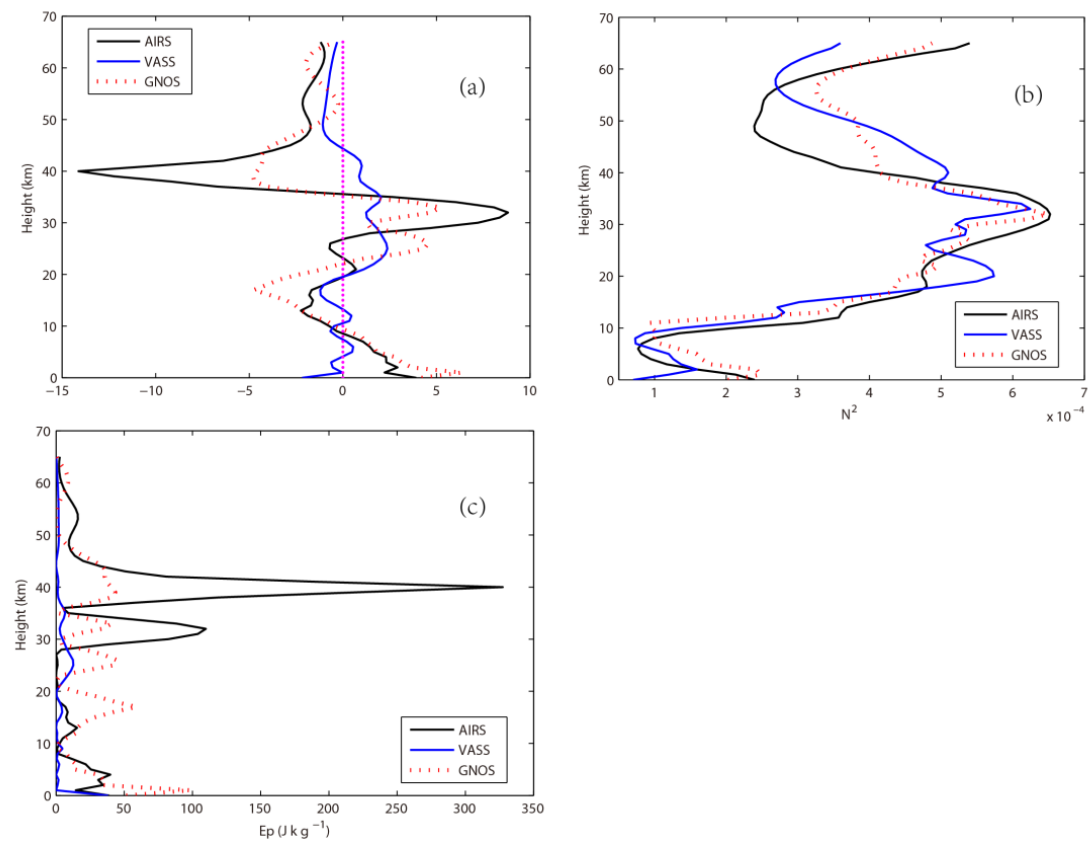

Figure 6. (a) Gravity wave temperature disturbance profile. (b) Gravity wave buoyancy frequency. (c) Gravity wave potential energy. Quantities are calculated using the single-filter method. Black lines indicate AIRS, blue lines VASS, and red dotted lines GNOS.

Comparing the gravity wave disturbance profiles (Fig. 6a), in the height range $5-35 \mathrm{~km}$, the gravity wave disturbance profile from GNOS is more consistent with that from AIRS. Meanwhile, AIRS and GNOS also reflect some small-scale fluctuation information, with wavelengths of about $3-5 \mathrm{~km}$. After the high-pass filtering, the vertical linear trend in the disturbance is filtered out well. The vertical 
460 variation of the obtained gravity wave disturbance is consistent with the results obtained using the double-filter method. Above $35 \mathrm{~km}$, the amplitude of the gravity wave disturbance from AIRS is larger than those from GNOS and VASS, reaching more than $8-10 \mathrm{~K}$ and $10-10 \mathrm{~K}$, with large height variation of VASS. As with the first two methods, from $5 \mathrm{~km}$ to $35 \mathrm{~km}$, GNOS has an even stronger gravity wave signal than AIRS. Above $35 \mathrm{~km}$, after the high-pass filtering, the vertical linear trend in the disturbance from AIRS is filtered out well. And this is also the case for the variation of the buoyancy frequency

(Fig. 6b) and the potential energy of the gravity wave (Fig. 6c).

In general, in the height range $5-35 \mathrm{~km}$, the gravity wave signal obtained by GNOS is better, and in the range $35-65 \mathrm{~km}$ the gravity wave signal obtained by AIRS is better. Because of the lower vertical resolution of VASS, the gravity wave signal obtained by VASS is different from AIRS and GNOS. The gravity wave disturbance extracted by the single-filter method is generally very accurate. The gravity wave disturbance obtained using the single-filter method essentially does not contain a large-scale background in the vertical direction, but still contains some small-vertical-scale disturbances.

\section{Conclusions}

In order to further investigate the advantages and disadvantages of FY-3, the two types of temperature profile products from FY-3, with GNOS and VASS, together with AIRS operational Level 2 data, are used to compare and analyze the gravity wave parameter based on three extraction methods. The main results are as follows:

1. The results calculated by the three methods are generally consistent. However, they have advantages and disadvantages. First, the vertical sliding average method can extract gravity wave disturbances with a vertical wavelength of less than $8 \mathrm{~km}$. However, because of the overestimation of gravity wave disturbance near the tropopause, accurate gravity wave disturbance profiles are not available.

2. Second, the double-filter method can extract gravity waves with a vertical wavelength range from 2 to $10 \mathrm{~km}$. The gravity wave disturbance value obtained by this method is more accurate.

3. Third, the single-filter method can obtain gravity wave disturbances in the vertical wavelength range from 2 to $8 \mathrm{~km}$, but the gravity wave disturbance profiles obtained using this method still contain some small-vertical-scale disturbances. Due to linear interpolation, each profile resolution reduces to $1 \mathrm{~km}$. 4. In comparing the three gravity wave parameter extraction methods, it is found that the GNOS temperature profile product has better results in the lower layer of 5-35 km. From 35 to $65 \mathrm{~km}$ AIRS is better than GNOS. From 5 to $35 \mathrm{~km}$, when the double-filter or single-filter method is used, GNOS contains small-scale information. Using the single-filter method, GNSS and AIRS filter out the vertical linear trend in the disturbance profile well, reflecting an advantage of this method. The vertical resolution of VASS is lower, but larger vertical scale components are retained. 
Data Availability. The data used in this paper are available from the corresponding author upon request.

Author contributions. The central idea is mainly contributed by ZS and SC. The methods used in this manuscript are conceived by ZS and WG. The retrieval algorithm is developed SC, ZS and WG. The results are discussed by SC, ZS and WG. SC analyzed the data, prepared the figures and wrote the paper. WZ, YH and ZL contributed to refining the ideas, carrying out additional analyses. All co-authors reviewed the paper.

Competing interests. The authors declare that they have no conflict of interest.

Acknowledgements. The study was supported by the National Key R\&D Program of China (No.

(Grant no. 41875045).

\section{References}

Alexander, M.J., and Pfister, L.: Gravity wave momentum flux in the lower stratosphere over convection, Geophys. Res. Lett., 22, 2029-2032, https://doi.org/10.1029/95GL01984, 1995. seasonal and interannual variability, J. Geophys. Res. Atmos., 105, 17983-17993, https://doi.org/10.1029/2000JD900196, 2000.

Alexander, M. J., Gille, J., Cavanaugh, C., Coffey, M., Craig, C., Eden, T., Francis, G., Halvorson, C., Hannigan, J., Khosravi, R., Kinnison, D., Lee, H., Massie, S., Nardi, B., Barnett, J., Hepplewhite, C., Lambert, A., and Dean, V.: Global estimates of gravity wave momentum flux from high resolution dynamics limb sounder observations, J. Geophys. Res., 113, D15S18, https://doi.org/10.1029/2007JD008807, 2008.

Alexander, M.J., Geller, M., McLandress, C., Polavarapu, S., Preusse, P., Sassi, F., Sato, K., Eckermann, S., Ern, M., Hertzog, A., Kawatani, Y., Pulido, M., Shaw, T.A., Sigmond, M., Vincent, R., and distribution of gravity-wave momentum flux from observations and models, Q.J.R. Meteorol. Soc., 136, 1103-1124, https://doi.org/10.1002/qj.637, 2010.

Alexander, S.P., Tsuda, T., Kawatani, Y., and Takahashi, M.: Global distribution of atmospheric waves in the equatorial upper troposphere and lower stratosphere: COSMIC observations of wave mean 
Aumann, H.H.: Atmospheric infrared sounder on the Earth Observing System: in-orbit spectral calibration, Optl. Engr., 33, 776-784, https://doi.org/10.1117/12.159325, 1994.

Dee, D.P., Uppala, S.M., Simmons, A.J., Berrisford, P., Poli, P., Kobayashi, S., Andrae, U., Balmaseda, M.A., Balsamo, G., Bauer, P., Bechtold, P., Beljaars, A.C., Berg, L.V.D., Bidlot, J., Bormann, N., Delsol, C., Dragani, R., Fuentes, M., Geer, A.J., Haimberger, L., Healy, S.B., Hersbach, H., Holm, E.V., Isaksen, L., Kållberg, P., Köhler, M., Matricardi, M., McNally, A.P., Monge-Sanz, B.M., Morcrette, J., Park, B., Peubey, C., Rosnay, P.D., Tavolato, C., Thepaut, J., and Vitart, F.: The ERA-Interim reanalysis: configuration and performance of the data assimilation system, Q.J.R. Meteorol. Soc., 137, 553-597, https://doi.org/10.1002/qj.828, 2011.

Durran, R., Klemp. B.: Another look at downslope winds. Part II: nonlinear amplification beneath wave-overturning layers, J. Atmos. Sci., 44, 3402-3412, https://doi.org/10.1175/1520-0469(1987)044<3402:ALADWP>2.0.CO;2, 1987.

Ern, M., Ploeger, F., Preusse, P., Gille, J. C., Gray, L. J., Kalisch, S., Mlynczak, M. G., Russell, J. M., and Riese, M.: Interaction of gravity waves with the QBO: A satellite perspective, J. Geophys. Res. Atmos., 119, 2329-2355, https://doi.org/10.1002/2013JD020731, 2014.

Ern, M., Hoffmann, L., and Preusse, P.: Directional gravity wave momentum fluxes in the stratosphere derived from high-resolution AIRS temperature data, Geophys. Res. Lett., 44, 475-485., https://doi.org/10.1002/2016GL072007, 2017.

Fetzer, E.J., and Gille, J.C.: Gravity wave variance in lims temperatures. Part I: variability and comparison with background winds, J. Atmos. Sci., 51, 2461-2483, https://doi.org/10.1175/1520-0469(1994)051<2461:GWVILT>2.0.CO;2, 1994.

Fritts, D.C., and Nastrom, G.D.: Sources of mesoscale variability of gravity waves. Part II: frontal, convective, and jet stream excitation, J. Atmos. Sci., 49, 111-127, https://doi.org/10.1175/1520-0469(1992)049<0111:SOMVOG>2.0.CO;2, 1992.

Fritts, D. C., and Alexander, M. J.: Gravity wave dynamics and effects in the middle atmosphere, Rev. Geophys., 41, 1003, https://doi.org/10.1029/2001RG000106, 2003.

Gong, J., Wu, D. L., and Eckermann, S. D.: Gravity wave variances and propagation derived from AIRS radiances, Atmos. Chem. Phys., 12, 1701-1720, https://doi.org/10.5194/acp-12-1701-2012, 2012.

Hindley, N.P., Wright, C.J., Smith, N.D., Hoffmann, L., Holt, L.A., Alexander, M.J., Moffat-Griffin, T., and Mitchell, N. J.: Gravity waves in the winter stratosphere over the Southern Ocean: high-resolution satellite observations and 3-D spectral analysis, Atmos. Chem. Phys., 371, 1-50, https://doi.org/10.5194/acp-2019-371, 2019.

Hocke, K., and Tsuda, T.: Gravity waves and ionospheric irregularities over tropical convection zones observed by GPS/MET radio occultation. Geophysical Research Letters, 28, 2815-2818. 
Hoffmann, L., and Alexander, M.J.: Retrieval of stratospheric temperatures from Atmospheric Infrared Sounder radiance measurements for gravity wave studies, J. Geophys. Res., 114, D07105, https://doi.org/10.1029/2008JD011241, 2009.

Hoffmann, L., Xue, X., and Alexander, M. J.: A global view of stratospheric gravity wave hotspots located with Atmospheric Infrared Sounder observations, J. Geophys. Res. Atmos., 118, 416-434, https://doi.org/10.1029/2012JD018658, 2013.

Hoffmann, L., Alexander, M. J., Clerbaux, C., Grimsdell, A. W., Meyer, C. I., Rößler, T., and Tournier, B.: Intercomparison of stratospheric gravity wave observations with AIRS and IASI, Atmos. Meas. Tech., 7, 4517-4537, https://doi.org/10.5194/amt-7-4517-2014, 2014.

Holton, J.R.: The role of gravity wave induced drag and diffusion in the momentum budget of the mesosphere, J. Atmos. Sci., 39, 791-799, https://doi.org/10.1175/1520-0469(1982)039<0791:TROGWI>2.0.CO;2, 1982.

Holton, J.R.: The influence of gravity wave breaking on the general circulation of the middle atmosphere, J. Atmos. Sci., 40, 2497-2507, https://doi.org/10.1175/1520-0469(1983)040<2497:TIOGWB>2.0.CO;2, 1983.

Kim, Y.J., Eckermann, S.D., and Chun, H.Y.: An overview of the past, present and future of gravitywave drag parametrization for numerical climate and weather prediction models, AtmosphereOcean, 41, 65-98, https://doi.org/10.3137/ao.410105, 2003. wave breaking: Observation and modeling, J. Geophys. Res. Atmos., 101, 22969-22976, https://doi.org/10.1029/96JD02442, 1996.

Lane, T.P., R.D. Sharman, T.L. Clark, and Hsu H.: An investigation of turbulence generation mechanisms above deep convection, J. Atmos. Sci., 60, 1297-1321, https://doi.org/10.1175/1520-0469(2003)60<1297:AIOTGM>2.0.CO;2, 2003.

Li, W., and Yi, F.: Characteristics of inertia-gravity waves around jet stream from radiosonde observations in Wuhan $\left(30.5^{\circ} \mathrm{N}, 114.4^{\circ} \mathrm{E}\right)$, J. Atmos. Sol. Terr. Phys., 69, 826-834, https://doi.org/10.1016/j.jastp.2007.01.004, 2007.

Liang, C., Xue, X.H., and Chen, T.D.: An investigation of the global morphology of stratosphere gravity waves based on COSMIC observations, Chinese Journal of Geophysics, 57, 3668-3678, doi: 10.6038/cjg20141121, 2014.

Liao, Mi., Zhang, P., Yang, G.L., Bai, W.H., Meng, X.G., Du, Q.F., and Sun, Y.Q.: Status of radio occultation sounding technology of FY-3C GNOS, Advances in Meteorological Science and Technology, 6, 83-87, doi: 10.3969/j.issn.2095-1973.2016.01.012, 2016. 
in: remote sensing of clouds and the atmosphere XIX; and optics in Atmospheric in atmospheric propagation and adaptive systems XVII - validation of airs high-resolution stratospheric temperature retrievals, Proc. SPIE., 9242, 92420L, https://doi.org/10.1117/12.2066967, 2014.

Meyer, C. I., Ern, M., Hoffmann, L., Trinh, Q.T., and Alexander, M.J.: Intercomparison of AIRS and

Mcdonald, A.J.: Gravity wave occurrence statistics derived from paired COSMIC/FORMOSAT3 observations, J. Geophys. Res. Atmos., 117, D15106, doi:10.1029/2011JD016715, 2012.

Nastrom, G.D, and Fritts, D.C.. Sources of mesoscale variability of gravity waves. I: Topographic

excitation, J. Atmos. Sci., 49, 101-110, https://doi.org/10.1175/1520-0469(1992)049<0101:SOMVOG>2.0.CO;2 , 1992.

Pan, L.L., K.P. Bowman, Atlas E.L., Wofsy S.C., Zhang F., Bresch J.F., Ridley B.A., Pittman J.V., Homeyer C.R., Romashkin P., and Cooper W.A.: The stratosphere-troposphere analyses of regional transport 2008 experiment, Bull. Amer. Meteor. Soc., 91, 327-342, https://doi.org/10.1175/2009BAMS2865.1, 2010.

Pfister, L., Starr, W., Craig, R., Loewenstein, M., and Legg, M.: Small-scale motions observed by aircraft in the tropical lower stratosphere: evidence for mixing and its relationship to large-scale flows, J. Atmos. Sci., 43, 3210-3225, https://doi.org/10.1175/1520-0469(1986)043<3210:SSMOBA>2.0.CO;2, 1986.

Plougonven, R., Teitelbaum, H., and Zeitlin, V.: Inertia gravity wave generation by the tropospheric midlatitude jet as given by the Fronts and Atlantic Storm-Track Experiment radio soundings, J. Geophys. Res., 108, 4686, doi:10.1029/2003JD003535, D21, 2003.

Ratnam, M. V., Tetzlaff, G., and Jacobi, C.: Global and seasonal variations of stratospheric gravity wave activity deduced from the CHAMP/GPS satellite, J. Atmos. Sci., 61, 1610-1620. https://doi.org/10.1175/1520-0469(2004)061<1610:GASVOS>2.0.CO;2, 2004.

Smith, R.B.: On severe downslope winds, J. Atmos. Sci., 42, 2597-2603, https://doi.org/10.1175/1520-0469(1985)042<2597:OSDW>2.0.CO;2, 1985.

Sprenger, M., Wernli, H., and Bourqui, M.: Stratosphere-troposphere exchange and its relation to potential vorticity streamers and cutoffs near the extratropical tropopause, J. Atmos. Sci., 64, 1587-1602, https://doi.org/10.1175/JAS3911.1, 2007.

Sun, R., Yao, Z.G., Han, Z.G., Zhao, Z.L., Cui, X.D., Yan, W.: Numerical simulation of stratospheric gravity waves induced by a rainstorm, Chin. J. Space Sci., 38, 469-481, doi:10.11728/cjss2018.04.469, 2018.

Tang, Y., Dou, X., Li, T., Nakamura, T., Xue, X., Huang, C., Manson, A., Meek, C., Thorsen, D., and Avery, S.: Gravity wave characteristics in the mesopause region revealed from $\mathrm{OH}$ airglow imager 
observations over Northern Colorado, J. Geophys. Res. Space Physics., 119, 630-645,

https://doi.org/10.1002/2013JA018955, 2014.

Torre, A.D.L., Schmidt, T., and Wickert, J.: A global analysis of wave potential energy in the lower stratosphere derived from 5 years of GPS radio occultation data with CHAMP, Geophys. Res. Lett., 33, L24809, https://doi.org/10.1029/2006GL027696, 2006.

Tsuda, T., Murayama, Y., Wiryosumarto, H., Harijono, S.W.B., and Kato, S.: Radiosonde observations of equatorial atmosphere dynamics over Indonesia: 2. Characteristics of gravity waves, J. Geophys. Res. Atmos., 99, 10507-10516, https://doi.org/10.1029/94JD00354, 1994.

Tsuda, T., Nishida, M., Rocken, C., and Ware, R. H.: A global morphology of gravity wave activity in the stratosphere revealed by the GPS occultation data (GPS/MET), J. Geophys. Res., 105, 72577273, https://doi.org/10.1029/1999JD901005, 2000.

Vadas, S.L., Fritts, D.C., and Alexander, M.J.: Mechanism for the generation of secondary waves in wave breaking regions, J. Atmos. Sci., 60, 194-214, https://doi.org/10.1175/1520-0469(2003)060<0194:MFTGOS>2.0.CO;2, 2003. stratosphere over Korla, Xinjiang. Chinese J. Geophys. 61(9), 3560-3566. doi:10.6038/cjg2018K0095.

Wang, L., and Alexander, M.J.: Gravity wave activity during stratospheric sudden warmings in the 2007-2008 Northern Hemisphere winter, J. Geophys. Res., 114, D18108, https://doi.org/10.1029/2009JD011867, 2009.

Wang, Y.Z., Huang, Y.Y., Li H.J., and Li C.Y.: Analysis of stratospheric gravity wave parameters based on COSMIC observations, Chin. J. Space Sci., 39, 326-341, doi:10.11728/cjss2019.03.326, 2019.

Williams, P.D., and Joshi, M.M.: Intensification of winter transatlantic aviation turbulence in response to climate change, Nature Climate Change, 3, 644, https://doi.org/10.1038/nclimate1866, 2013.

Wright, C.J., Hindley, N.P., Hoffmann, L., Alexander, M.J., and Mitchell, N.J.: Exploring gravity wave characteristics in 3-D using a novel S-transform technique: AIRS/Aqua measurements over the Southern Andes and Drake Passage, Atmos. Chem. Phys., 17, 8553-8575, https://doi.org/10.5194/acp-17-8553-2017, 2017.

Wu, D. L., and Zhang, F.: A study of mesoscale gravity waves over the North Atlantic with satellite observations and a mesoscale model, J. Geophys. Res., 109, D22104, doi:10.1029/2004JD005090, 2004.

Wu, D.L., and Eckermann, S.D.: Global gravity wave variances from Aura MLS: characteristics and interpretation, J. Atmos. Sci., 65, 3695-3718, https://doi.org/10.1175/2008JAS2489.1, 2008.

Xiao, C.Y., and Hu, X.: Analysis on the global morphology of stratospheric gravity wave activity deduced from the COSMIC GPS occultation profiles, Gps Solutions, 14, 65-74, 
Yao, Z.G., Zeng, L.Z., and Han, Z.G.: Stratospheric gravity waves during summer over East Asia derived from airs observations, Chinese J. Geophys., 58, 1121-1134, doi:10.6038/cjg20150403, 2015.

Yao, Z.G., Sun, R., Zhao, Z.L., Cui, X.L., Han, Z.G., and Yan, W.: Gravity waves in the near space observed by the microwave temperature sounder of the FY-3C meteorology satellite, Chinese J. Geophys., 62, 473-488, doi: 10.6038/cjg2019L0481, 2019.

Zhang, S. D., Yi, F., Huang, C. M., and Zhou, Q.: Latitudinal and seasonal variations of lower atmospheric inertial gravity wave energy revealed by US radiosonde data, Ann. Geophys., 28, 1065-1074, https://doi.org/10.5194/angeo-28-1065-2010, 2010. 